\title{
Classic Kaposi's sarcoma in Italy, 1985-1998
}

\section{Dal Maso ${ }^{*, 1}$, J Polesel', V Ascoli ${ }^{2}$, P Zambon ${ }^{3}$, M Budroni $^{4}$, S Ferretti ${ }^{5}$, R Tumino ${ }^{6}$, G Tagliabue ${ }^{7}$, S Patriarca $^{8}$, M Federico', M Vercelli ${ }^{10}$, A Giacomin ${ }^{11}, G$ Vicario ${ }^{1,12}, \mathrm{~F}$ Bellù $^{13}, \mathrm{~F} \mathrm{Falcini}^{14}, \mathrm{E} \mathrm{Crocetti}^{15}, \mathrm{~V}$ De Lisi $^{16}$, S Vitarelli ${ }^{17}$, S Piffer ${ }^{18}$, F Stracci ${ }^{19}$, D Serraino ${ }^{20}$, G Rezza $^{21}$ and S Franceschi ${ }^{22}$ for the Cancer and AIDS Registry Linkage (CARL) Study ${ }^{23}$}

\begin{abstract}
'Servizio di Epidemiologia e Biostatistica, Centro di Riferimento Oncologico IRCCS, Via Pedemontana Occ.le 12, 3308 I Aviano, Italy; ${ }^{2}$ Dipartimento di Medicina Sperimentale e Patologia, Università La Sapienza, Viale Regina Elena 324, 00161 Rome, Italy; ${ }^{3}$ Università di Padova, Registro Tumori del Veneto, Via Gattamelata 64, 35128 Padua, Italy; ${ }^{4}$ Registro Tumori della Provincia di Sassari, Centro Multizonale di Osservazione Epidemiologica, Via Tempio 5, 07100 Sassari, Italy; ${ }^{5}$ Registro Tumori della Provincia di Ferrara, Sezione di Anatomia, Istologia e Citologia Patologica, Via Fossato di Mortara 64, 44100 Ferrara, Italy; ${ }^{6}$ Registro Tumori Azienda Ospedaliera Civile 'MP Arezzo', Via Dante 109, 97100 Ragusa, Italy; ${ }^{7}$ Registro Tumori Lombardia Provincia di Varese, Istituto Nazionale Tumori, Via Venezian 8, 20133 Milan, Italy; ${ }^{8}$ Registro Tumori del Piemonte, Ospedale S Giovanni Antica Sede, Via S Francesco da Paola 31, 10123 Turin, Italy; ${ }^{9}$ Registro Tumori della Provincia di Modena, Policlinico, Via Dal Pozzo 71, 41 I 00 Modena, Italy; ${ }^{10}$ Registro Tumori Ligure, Istituto Nazionale per la Ricerca sul Cancro, Largo Rosanna Benzi 10, 16132 Genoa, Italy; "'Registro Tumori della Provincia di Biella, Azienda Sanitaria Locale 12, Via Don Sturzo 20, 13900 Biella, Italy; ${ }^{2}$ Registro Tumori del Friuli-Venezia Giulia, Agenzia Regionale di Sanità, Piazzale S Maria della Misericordia 15, 33100 Udine, Italy; ${ }^{13}$ Registro Tumori dell'Alto Adige, Corso Italia I3/M, 39I00 Bolzano, Italy; ${ }^{14}$ Registro Tumori della Romagna, Istituto Oncologico Romagnolo, Dipartimento Oncologico, Ospedale Pierantoni, Via Forlanini II, 47 I 00 Forli, Italy; ${ }^{15}$ Epidemiologia clinica e descrittiva, Centro Studio e Prevenzione Oncologica, Via di S Salvi 12, 50135 Florence, Italy; ${ }^{16}$ Registro Tumori della Provincia di Parma, Ospedale di Parma, Via Gramsci 14, 43100 Parma, Italy; ${ }^{17}$ Registro Tumori di Macerata, Università di Camerino, Viale E Betti 3, 62032 Camerino, Italy; ${ }^{18}$ Registro Tumori della Provincia di Trento, Ossenvatorio Epidemiologico, Via Gilli 3, 38100 Trento, Italy; ${ }^{19}$ Registro Tumori Umbro di Popolazione, Università di Perugia, Via del Giochetto, 06123 Perugia, Italy; ${ }^{20}$ Dipartimento di Epidemiologia, INMI 'L Spallanzani' IRCCS, Via Portuense 292, 00149 Rome, Italy; ${ }^{21}$ Istituto Superiore di Sanità, Viale Regina Elena 299, 00161 Rome, Italy; ${ }^{22}$ International Agency for Research on Cancer, 150 cours A Thomas, 69372 Lyon, France
\end{abstract}

To evaluate incidence rates (IRs) of classic Kaposi's sarcoma (CKS) in Italy after the spread of AIDS, we distinguished CKS from AIDSrelated KS (AKS) using an 'ad hoc' record linkage procedure between 15 Cancer Registries (CRs) (21\% of the Italian population) and the national AIDS Registry. Between 1985 and 1998, 874 cases of CKS and 634 cases of AKS were diagnosed in the study areas. CKS accounted for 16 and $27 \%$ of KS cases below 55 years of age in men and women, respectively, but for 91 and $100 \%$ of those above age 55. The IRs for CKS were I.0/ in men and 0.4/100000 in women, but they varied between 0.3 in Umbria and 4.7 in Sassari in men, and between 0.1 in Parma and I.7 in Sassari in women. IRs of CKS in both genders were stable between $1985-1987$ and 1993-1998. In Northern and Central CRs the IR (adjusted for age and gender) for CKS was 0.5 in individuals born in the same area, but 1.6 in individuals born in Southern Italy or in the Islands (rate ratio = 3.2) suggesting that KS-associated herpesvirus, the cause of $\mathrm{KS}$, is acquired early in life.

British Journal of Cancer (2005) 92, I88-193. doi:I0.1038/sj.bjc.6602265 www.bjcancer.com

Published online 30 November 2004

(C) 2005 Cancer Research UK

Keywords: classic Kaposi's sarcoma; incidence; Cancer Registries; Italy

Before the AIDS epidemic, Kaposi's sarcoma (KS) occurred sporadically in Europe, most notably in elderly men of Mediterranean or Middle Eastern origin (classic KS, CKS) (Franceschi and Geddes, 1995). Some increase in incidence was reported in the 1960 s and 1970s and attributed to the increase in immunosuppressive treatment (e.g. corticosteroid use) (Dictor and Attewell, 1988).

*Correspondence: Dr L Dal Maso, Servizio di Epidemiologia e Biostatistica, Centro di Riferimento Oncologico IRCCS, Via Pedemontana Occ.le 12, 3308I Aviano (PN), Italy; E-mail: epidemiology@cro.it

${ }^{23}$ See Appendix.

Received 3 June 2004; revised 15 October 2004; accepted 20 October 2004; published online 30 November 2004
Since the 1980s, consequent on the AIDS epidemic, KS incidence has increased in all Western countries (Dal Maso et al, 1999), mainly due to the high frequency of AIDS-associated KS (AKS) among HIV-infected homosexual and bisexual males (IARC, 1996). KS-associated herpesvirus (KSHV or human herpesvirus type 8, HHV8) is recognised as the necessary, though not sufficient, cause of all clinical variants of KS (Moore and Chang, 1998; Iscovich et al, 2000).

Owing to the rise in AKS incidence, the evaluation of CKS incidence trends has become difficult. KS rates in older persons (e.g. $\geqslant 65$ years), who have an extremely low prevalence of HIV/ AIDS, have been used as a proxy for CKS rates (Geddes et al, 1994; Hjalgrim et al, 1998). Other studies manually reviewed medical records of KS cases to distinguish major KS types (Ascoli et al, 2001; Santarelli et al, 2001). Automatic linkage procedures 
(Franceschi et al, 2003) provide a powerful tool to distinguish CKS from AKS in populations where Cancer Registries (CRs) and HIV/ AIDS Registries both exist (Guttman-Yassky et al, 2003), and we applied this approach in our Italian study.

\section{MATERIALS AND METHODS}

CKS and AKS were distinguished using the record-linkage procedure of Cancer and AIDS Registries Linkage (CARL) study (Dal Maso et al, 2003). Several independent CRs, covering a population of 11.6 million ( $21 \%$ of the total Italian population), have produced accurate KS incidence rates (IRs) for the mid-1990s (Parkin et al, 2002; Zanetti et al, 2002). They covered the 'NorthEast network', including the Friuli-Venezia Giulia region and the provinces of Trento and Alto Adige, the regions of Romagna and Umbria, part of the Veneto region, the municipality of Turin, the provinces of Biella, Genoa, Varese, Parma, Modena, Ferrara, Macerata, Florence and Prato, Sassari and Ragusa. CRs varied in size, ranging from populations of approximately 190000 to 2 million, as well as in the number of registration years available (Parkin et al, 2002; Dal Maso et al, 2003).

AIDS notification in Italy started in 1982 and has been mandatory since 1986. By the end of the year 2000, 47503 AIDS cases had been recorded according to the clinical standard definitions (Istituto Superiore di Sanità, 2003).

An 'ad hoc' software application (Software for Automated Linkage in Italy, SALI) was developed to perform the record linkage procedure (Dal Maso et al, 2001a). Briefly, records from the Italian AIDS registry (RAIDS) and CRs are linked by first and last name, and by date of birth. Satisfaction of the name-date algorithm requires: (a) that the records are identical for at least one critical field; and (b) that the other two critical fields, if not identical, differ only in prescribed ways. Personal identifiers are removed during linkage procedures; thus, the staff of each registry is blinded to which persons have been linked. SALI has been shown to have a very high sensitivity and specificity in the Italian context, and it is available upon request (Dal Maso et al, 2001a).

The present study was restricted to people who: (1) were diagnosed with KS between 1985 and 1998; (2) reported legal residence in areas covered by CRs; and (3) had KS in periods deemed complete by both CRs and RAIDS. All ages were included.

KS cases were considered AIDS-related when: (a) they occurred in patients with AIDS notified at RAIDS; (b) AIDS was one of the three causes mentioned on the death certificate; (c) HIV-infection was mentioned in any additional medical record available at the
CR (e.g. HIV-positive test or mention of AIDS-related disease at hospital admission or death). A total of 16 unlinked KS were reclassified as AKS according to criteria (b) and (c), otherwise the KS cases were considered as CKS.

Nine KS cases were excluded because they arose in the transplant patients, information recorded in only three CRs (Genoa, Sassari and Veneto). One KS case notified only by death certificate and three for whom the type of diagnosis (e.g. clinical, histological, etc) was unknown were also excluded.

Standardised IRs were computed by gender, place of residence, place of birth and overall using the direct method (Breslow and Day, 1987) and the 1991 Italian population as standard population. Rate ratios (RR) adjusted by age and gender were calculated by place of birth, and 95\% percent confidence intervals (CI) were computed according to the Poisson distribution (Breslow and Day, 1987). To evaluate temporal trends, IRs were computed separately into three periods: (a) 1985-1987 (Parkin et al, 1992); (b) 19881992 (Parkin et al, 1997) and (c) 1993-1998 (Parkin et al, 2002).

\section{RESULTS}

Between 1985 and 1998, 874 CKS and 634 AKS were reported to Italian CRs (Table 1). The age distribution of CKS was similar for men and women, the median age was 72 years (range 18-95), and only $119(14 \%)$ occurred in persons below age 55. Conversely, AKS occurred at a median age of 36 (range 19-83) and only $49(8 \%)$ were diagnosed at age 55 or above.

With respect to site of cancer presentation, skin predominated in both CKS (88\%) and AKS (86\%) but skin of the leg and hip was more frequently involved in CKS than in AKS (Table 1). In total, $10 \%$ of AKS was diagnosed in the lip, oral cavity, pharynx and digestive organs compared to only $3 \%$ of CKS.

Figure 1 shows the age-specific IRs of CKS and all KS in all Italian study areas in the period 1985-1998. It is noteworthy that in Italy CKS accounted for 91.0 and $100 \%$ of new cases of KS, respectively, in men and women aged 55 years or older in Italy, but only 15.7 and $26.9 \%$, respectively, below that age. No significant correlation emerged between IRs of CKS and AKS in different areas (Spearman coefficient, $r=-0.16$ in men and 0.38 in women, data not shown).

Table 2 shows CKS IRs by gender and place of residence. Overall, the IRs were $0.98 / 100000$ men and $0.41 / 100000$ women. However, a wide heterogeneity emerged, with IRs between 0.3 in Umbria (Central Italy) to 4.7 in Sassari (Sardinia, Southern Italy) in men, and between 0.1 in Parma (Northern Italy) to 1.7 in Sassari

Table I Observed (Obs) cases of classic and AIDS-related Kaposi's sarcoma (KS) by site of presentation in I5 Italian Cancer Registries, I985-1998

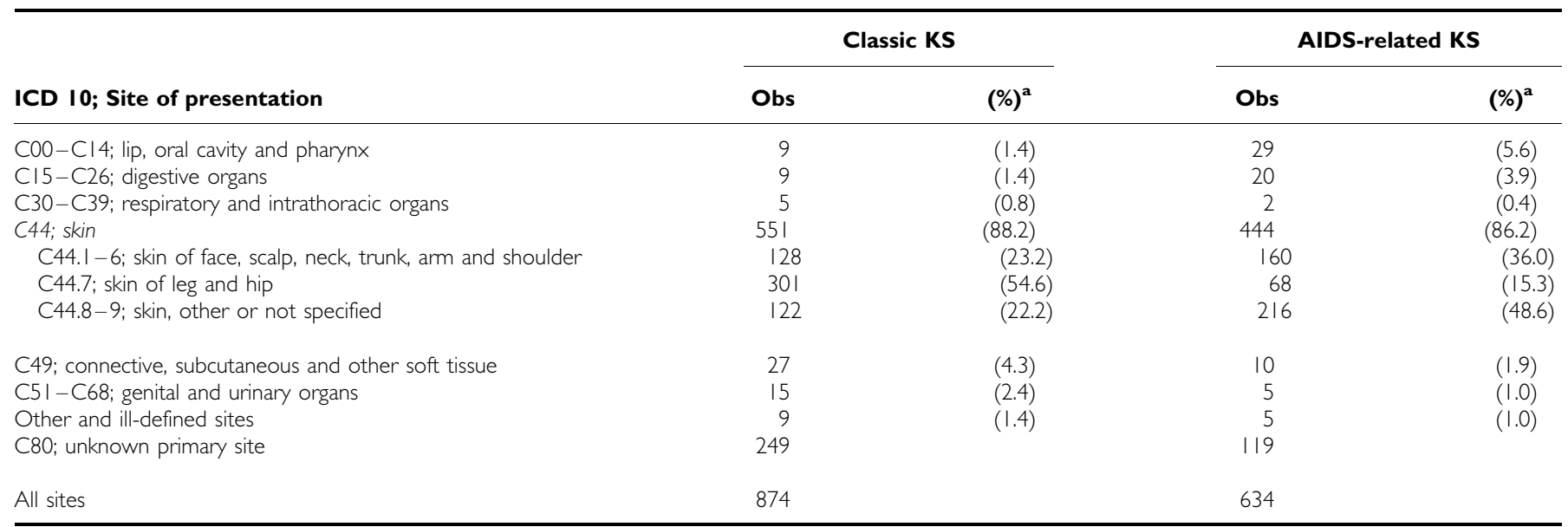

anknown primary site excluded from the calculation. 

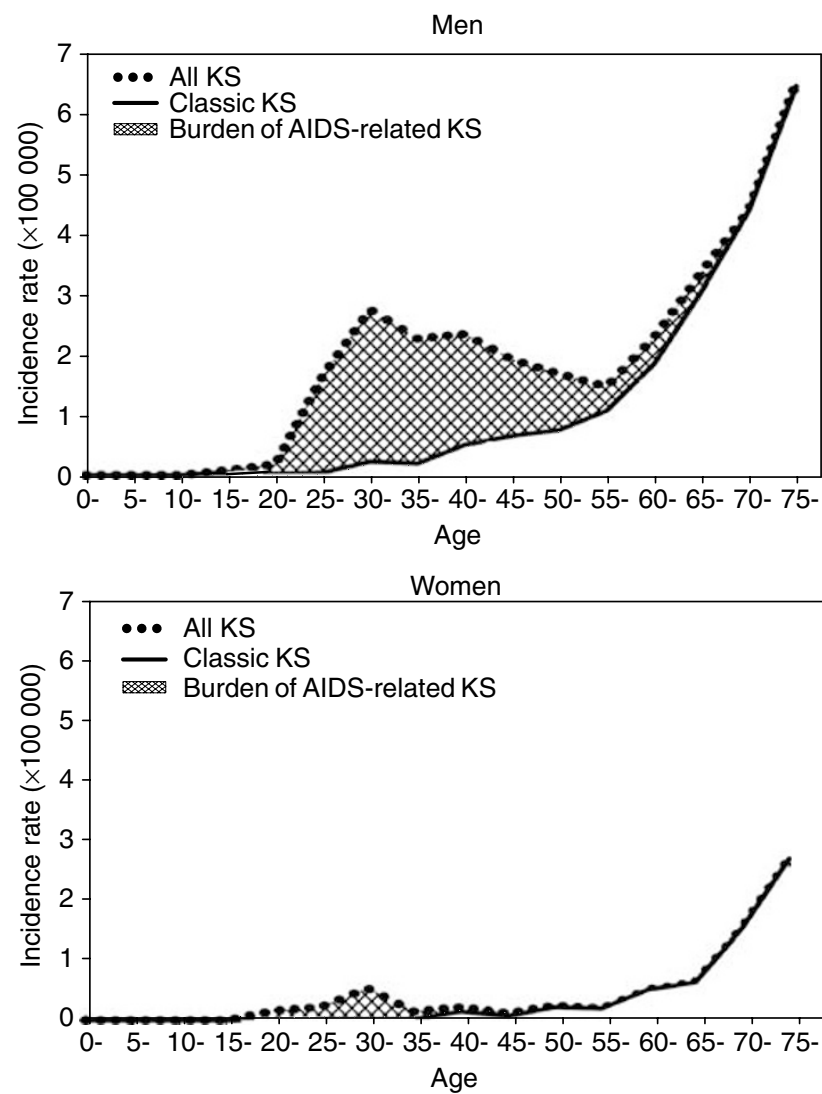

Figure I Incidence rates of classic Kaposi's sarcoma (KS) and all KS by age in 15 Italian Cancer Registries and burden of AIDS-related KS in men and women, $1985-1998$ in women (Table 2). Central Italy showed the lowest IRs while, in Northern Italy, the IRs in Ferrara were similar to those in Ragusa (Sicily) and significantly higher than those in nearby areas in both genders. Three-fold higher IRs were found in the two CRs from Southern Italy, mainly on account of particularly elevated IRs in Sassari.

A high positive correlation $(r=0.66)$ between IRs in men and women emerged. Thus, male-female ratios were generally between 2.0 and 2.5 in most of the areas, despite some probability of random variation.

The association of place of birth and CKS was evaluated in Northern and Central CRs (Table 3). Among CKS cases in Northern and Central Italy, the IR was 0.5 for individuals born in the same area, while it was 1.6 for individuals born in Southern Italy or in the Islands ( $\mathrm{RR}=3.2$; 95\% CI: 3.2-3.3). The RRs for individuals born in the South or in the Islands were particularly elevated in the North-East (7.0) and Umbria (9.5), but close to unit in Ferrara (1.7) and Varese (1.6).

Figure 2 shows trends in the CKS incidence and, for comparison purposes, for all KS in the seven CRs that had been active since 1985. CKS IRs in men slightly increased between 1985-1987 $(\mathrm{IR}=0.7)$ and 1988-1992 (1.0) but did not change thereafter (1.1 in 1993-1998). In women, the IRs were between 0.3 and 0.4 throughout the considered period. By contrast, consequent to the steady increase of people with HIV/AIDS, the incidence of all KS increased from 1.1 and 0.3 in $1985-1987$ to 2.9 and 0.6 in $1993-$ 1998 in men and women, respectively.

\section{DISCUSSION}

Our study is one of the first attempts (Guttman-Yassky et al, 2003) to describe the epidemiology of CKS in a large population after the huge increase of KS caused by the AIDS epidemic (Dal Maso et al, 2001b). A many-fold higher incidence of CKS, compared to

Table 2 Observed (Obs) cases, standardised incidence rates ${ }^{\mathrm{a}}(\mathrm{IR})$, and 95\% confidence intervals ${ }^{\mathrm{b}}(\mathrm{Cl})$ of classic Kaposi's sarcoma by gender in I5 Italian Cancer Registries, $1985-1998$

\begin{tabular}{|c|c|c|c|c|c|c|}
\hline \multirow[b]{2}{*}{ Cancer registry } & \multicolumn{3}{|c|}{ Male } & \multicolumn{3}{|c|}{ Female } \\
\hline & Obs & IR & $(95 \% \mathrm{Cl})$ & Obs & IR & $(95 \% \mathrm{Cl})$ \\
\hline Turin & 86 & 1.22 & $(0.98-1.51)$ & 35 & 0.43 & $(0.30-0.59)$ \\
\hline Biella & 2 & 0.44 & $(0.05-1.60)$ & 5 & 0.90 & $(0.28-2.14)$ \\
\hline Genoa & 72 & 1.17 & $(0.91-1.48)$ & 16 & 0.24 & $(0.14-0.39)$ \\
\hline Varese & 59 & 1.24 & $(0.94-1.60)$ & 28 & 0.53 & $(0.35-0.76)$ \\
\hline Parma & 23 & 0.65 & $(0.41-0.97)$ & 5 & 0.13 & $(0.04-0.30)$ \\
\hline Modena & 37 & 0.97 & $(0.68-1.33)$ & 24 & 0.59 & $(0.38-0.88)$ \\
\hline Ferrara & 38 & 1.68 & $(1.18-2.31)$ & 23 & 0.90 & $(0.57-1.36)$ \\
\hline Romagna & 38 & 0.70 & $(0.49-0.96)$ & 26 & 0.44 & $(0.29-0.64)$ \\
\hline \multicolumn{7}{|l|}{ Centre of Italy } \\
\hline Macerata & 6 & 0.45 & $(0.16-0.98)$ & 3 & 0.23 & $(0.04-0.70)$ \\
\hline \multicolumn{7}{|l|}{ South of Italy } \\
\hline Sassari & 60 & 4.69 & $(3.57-6.04)$ & 20 & 1.65 & $(1.00-2.55)$ \\
\hline Ragusa & 28 & 1.47 & $(0.98-2.13)$ & 15 & 0.92 & $(0.51-1.52)$ \\
\hline Total, South & 88 & 2.81 & $(2.25-3.46)$ & 35 & 1.23 & $(0.85-|.7|)$ \\
\hline Total, Italy & 595 & 0.98 & $(0.90-1.06)$ & 279 & 0.41 & $(0.36-0.46)$ \\
\hline
\end{tabular}

${ }^{a}$ Age-standardised (per 100000 population) according to Italian population, 1991. ' ${ }^{\mathrm{b} C o m p u t e d ~ a c c o r d i n g ~ t o ~ P o i s s o n ~ d i s t r i b u t i o n . ~}$ 
Table 3 Observed (Obs) cases of classic Kaposi's sarcoma, standardised incidence rates (IR) ${ }^{\mathrm{a}}$, rate ratio and $95 \%$ confidence intervals ${ }^{\mathrm{b}}(\mathrm{Cl})$ by place of birth and place of residence among individuals of both genders in 12 Northern and Central Italian Cancer Registries ${ }^{\mathrm{N}}, 1985-1998$

\begin{tabular}{|c|c|c|c|c|c|c|}
\hline Place of residence & \multicolumn{4}{|c|}{ Place of birth } & Rate Ratio ${ }^{f}$ & $(95 \% \mathrm{Cl})$ \\
\hline \multicolumn{7}{|l|}{ North of Italy } \\
\hline Turin & 85 & 2.08 & 34 & 0.37 & 5.6 & $(5.1-6.1)$ \\
\hline Biella & 0 & 0.00 & 7 & 0.78 & 0.0 & - \\
\hline North East & 12 & 2.66 & 29 & 0.38 & 7.0 & $(5.5-8.9)$ \\
\hline Veneto & 13 & 2.65 & 73 & 0.52 & 5.1 & $(4.3-6.2)$ \\
\hline Parma & 4 & 1.27 & 23 & 0.34 & 3.8 & $(2.0-7.0)$ \\
\hline Modena & 10 & 2.19 & 50 & 0.75 & 2.9 & $(2.2-3.9)$ \\
\hline Ferrara & 2 & 2.30 & 59 & 1.33 & 1.7 & $(0.6-4.9)$ \\
\hline Romagna & 6 & 1.82 & 56 & 0.53 & 3.4 & $(2.3-5.1)$ \\
\hline
\end{tabular}

${ }^{a}$ Standardised by age and gender (per 100000 population) according to Italian population, 1991. ' ${ }^{2}$ Computed according to Poisson distribution. Information is not available for

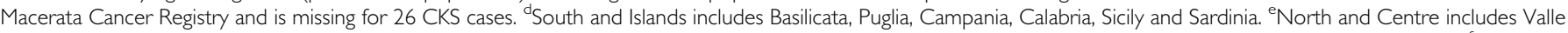
d'Aosta, Piedmont, Liguria, Lombardy, Trentino-Alto Adige, Veneto, Friuli-Venezia Giulia, Emila-Romagna, Tuscany, Lazio, Umbria, Marche, Abruzzo and Molise. 'South and Islands vs North and Centre.

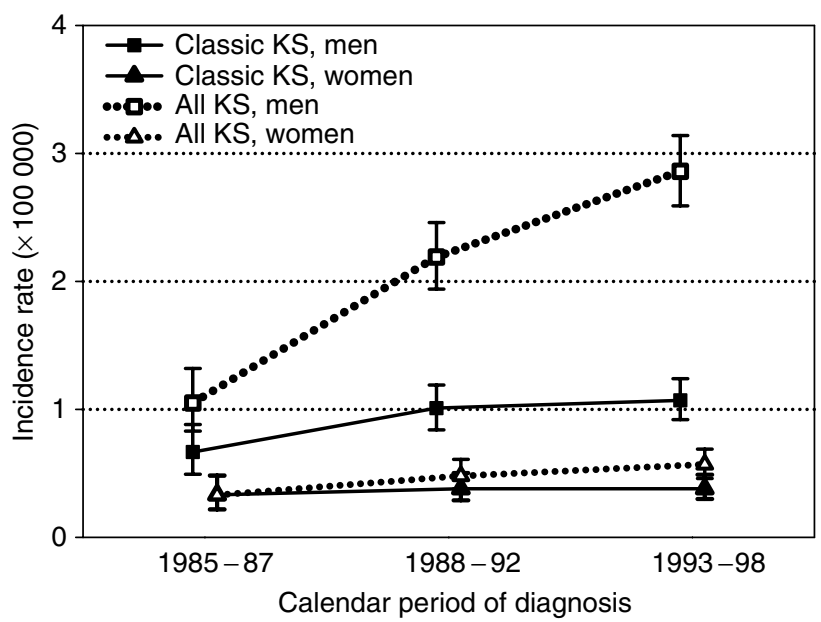

Figure 2 Age-standardised incidence rates (according to Italian population, 199I) and 95\% confidence intervals of classic Kaposi's sarcoma (KS) and all KS by year at diagnosis in seven Italian Cancer Registries (analyses have been restricted to Cancer Registries active since 1985 (i.e., Turin, Genoa, Varese, Parma, Romagna, Florence, and Ragusa), 1985-1998.

Northern Europe, the United States and Australia had already been recorded in Italy before 1985 (Geddes et al, 1994; Franceschi and Geddes, 1995; Cottoni et al, 1996).

A relatively high incidence of CKS was confirmed in the present study for the 1985-1998 period and the evidence of a broad within-country variation in both genders was expanded. The new CR in Sardinia, one of the only two available in the South and Islands, confirmed previous reports (Santarelli et al, 2001; Atzori et al, 2004) and showed a four-fold excess, compared to North (Ascoli et al, 2003) and Central Italy, where the majority of CRs are concentrated. However, high rates of CKS are also recorded in some areas in the North, notably in Ferrara, in the delta of the Po (Parkin et al, 2002).

The reasons for such variations in CKS are not well understood. In our present study, we showed that the incidence of CKS was mainly determined by place of birth but not by the place of living. Being born in the South of Italy was associated with a three-fold increased risk of CKS among individuals who lived in the North and Centre. The massive waves of migration from the rural South to industrial towns in the North, such as Genoa, Turin and Varese during the last century probably account for the moderate excess of CKS in the corresponding CRs compared to the national average.

Comparison with other countries is hampered by the difficulty in distinguishing CKS and AKS. IRs for all KS, in the second half of the 1990s, are available from 186 registries for 57 countries (Parkin et al, 2002). These range, in men, from less than 0.5/ 100000 in most CRs in Asia and Northern Europe, relatively spared by the AIDS epidemic, to 16.7/100000 in non-Hispanic Whites in San Francisco, California and 50.8/100000 in Harare, Zimbabwe (Parkin et al, 2002). Apart from Italy, recent population-based CKS IRs are only available for Israeli Jews. After excluding AKS cases, Guttman-Yassky et al (2003) reported for 1960-1998 a CKS incidence of 2.1/100000 for men and $0.8 / 100000$ for women, standardised using the world standard population. Using the same standard population, the IRs for Italy (0.6 in men and 0.2 in women) was lower than in Israel, but in Sardinia (2.6 in men and 0.6 in women) was similar to Israel. Substantial variations in the incidence of CKS were shown in Israel by country of origin, with approximately twofold higher IRs among Jews from Iraq, Morocco, and Romania compared to Jews who were born in Israel (Guttman-Yassky et al, 2003).

Our findings from Italy suggest substantial stability of CKS incidence between 1985 and 1998, as in Israel in the same period, when various Israeli subpopulations were taken into consideration (Guttman-Yassky et al, 2003). A male-to-female ratio of 2-to-3 is also similar in Italy and Israel. 
Despite some limitation of available data, the seroprevalence of KSHV antibodies in various geographic areas is correlated with the frequency of KS not associated to AIDS. The seroprevalence of KSHV antibodies is more than 25\% in Africa and below $10 \%$ in the United States and Europe (Whitby and Boshoff, 1998). Substantial variations, consistent with those reported here for CKS incidence, were also found between Italian regions, with seroprevalence below $10 \%$ in certain areas of the North (Calabrò et al, 1998; Whitby et al, 1998) but higher than $30 \%$ in the Islands of Sicily and Sardinia (Calabrò et al, 1998; Perna et al, 2000; Santarelli et al, 2001; Serraino et al, 2001).

Although sexual transmission is chiefly implicated in the high prevalence of KSHV among homosexual and bisexual men (Moore and Chang, 1998), other transmission routes have yet to be fully elucidated. KSHV is shed in saliva, like other viruses of the Herpes family (Wojcicki, 2003), and nonsexual transmission has been suggested to be the major route of transmission in Africa, where the infection is common in children (Mbulaiteye et al, 2003). Our findings concerning the importance of birth place, independently of place of residence, also suggest that in Italy early acquisition of KSHV infection is, or was, common in the middle-aged or elderly individuals with CKS in the present study. The excess of CKS in some Italian areas where wetlands and swamps are widespread (e.g. the Po delta, where Ferrara is located, and part of Sardinia) may have different explanations (Ascoli et al, 2001). These include a link between KS and malaria (Geddes et al, 1995) or, rather than malaria itself, the high-density of particular haematophagous insects (e.g. malaria vector Anopheles, black flies, sand flies, biting midges and mosquitoes). The practice of applying saliva to children's bite sites to relieve the itching and scratching may represent an efficient route of KSHV transmission (Coluzzi et al, 2003). Extensive land reclamation up to the 1960s and DDTspraying in the early $1950 \mathrm{~s}$ in malaria-endemic areas of Italy should have reduced this type of KSHV transmission (Coluzzi et al, 2003), but did not seem to have yet produced a decline of CKS, a disease chiefly of the elderly. Genetically increased susceptibility to KSHV infection and KS development in some Mediterranean

\section{REFERENCES}

Ajdaicic-Gross V, Zellweger U, Wang J, Fleerackers Y, Somaini B (2001) How complete is AIDS surveillance in Europe? An eagle eye comparison with mortality data. J Epidemiol Commun Health 55: 52 - 56

Ascoli V, Belli S, Benedetti M, Trinca S, Ricci P, Comba P (2001) High incidence of classic Kaposi's sarcoma in Mantua, Po Valley, Northern Italy (1989-1998). Br J Cancer 85: 379-382

Ascoli V, Zambon P, Manno D, Guzzinati S, Zorzi M, Arca B, Costantini C, Coluzzi M (2003) Variability in the incidence of classic Kaposi's sarcoma in the Veneto region, Northern Italy. Tumori 89: 122-124

Atzori L, Fadda D, Ferrelli C, Pastorelli C, Iannelli P, Rais M, Faa G, Cocco P, Aste N (2004) Classical Kaposi's sarcoma in southern Sardinia, Italy. Br J Cancer 91: $1261-1262$

Breslow NE, Day NE (1987) Statistical Methods in Cancer Research. Vol II. The Design and Analysis of Cohort Studies IARC Sci Publ No. 82. IARC: Lyon

Calabrò ML, Sheldon J, Favero A, Simpson GR, Fiore JR, Gomes E, Angarano G, Chieco-Bianchi L, Schulz TF (1998) Seroprevalence of Kaposi's sarcoma-associated herpesvirus/human herpesvirus 8 in several regions of Italy. J Hum Virol 1: 207-213

Coluzzi M, Calabrò ML, Manno D, Chieco-Bianchi L, Schulz TF, Ascoli V (2003) Reduced seroprevalence of Kaposi's sarcoma-associated herpesvirus (KSHV), human herpesvirus 8 (HHV8), related to suppression of Anopheles density in Italy. Med Vet Entomol 17: 1-4

Cottoni F, De Marco R, Montesu MA (1996) Classical Kaposi's sarcoma in north-east Sardinia: an overview from 1977 to 1991. Br J Cancer 72: $1132-1133$

Dal Maso L, Braga C, Franceschi S (2001a) Methodology used for 'Software for Automated Linkage in Italy' (SALI). J Biomed Informatics 34: 387-395 populations, including those from Southern Italy, is also a possibility (Iscovich et al, 2000).

The significance of our findings depends on the accurate distinction of CKS from other neoplasms and KS variants. The majority (96\%) of CKS reported here were histologically confirmed and, therefore, misclassification with sarcomas other than KS or with skin cancer can be ruled out. Misclassification of some AKS as CKS is of greater concern but should not account for our findings. AIDS registration in Italy is nationwide and has been shown to be almost complete (Ajdaicic-Gross et al, 2001). Moreover, in Italy, HIV-testing is routinely performed in patients with KS and CR staff reviewed medical records of all CKS cases. In very few KS (2\%), not matched with RAIDS, HIV-positivity or history of illnesses typically related to HIV or AIDS were found. Few cases of KS would have arisen because of severe iatrogenic immune suppression but, in the three CRs that systematically collected details of organ transplantation, only $3 \%$ of KS unrelated to AIDS had occurred in organ recipients.

In conclusion, between 1985 and 1998 in Italy, CKS accounted for $97 \%$ of all KS in elderly people ( $\geqslant 65$ years) and a nonnegligible fraction $(42 \%)$ of KS in men between 39 and 64 years. Presently, there is no evidence that the improvements in the standard of living in Italy over the last decades are causing a decline in this disease. Separation of CKS from AKS will be important in studies of the disease, especially now that HIVpositive individuals may live into old age.

\section{ACKNOWLEDGEMENTS}

This study is dedicated to the memory of Ettore MS Conti. This work was supported by the Istituto Superiore di Sanità, Rome, Grant No. 20D/1.1 and has received additional funding from Ministry of Health FSN 2002 Grant No. 122. We thank Dr Giorgio Luppi (Emilia Romagna statistical office) for providing the distribution of some Cancer Registry populations and Mrs Luigina Mei for editorial assistance.
Dal Maso L, Franceschi S, Lo Re A, La Vecchia C (1999) Comparison of the distribution of non-AIDS Kaposi's sarcoma and non-Hodgkin's lymphoma in Europe. Br J Cancer 79: $161-163$

Dal Maso L, Franceschi S, Polesel J, Braga C, Piselli P, Crocetti E, Falcini F, Guzzinati S, Zanetti R, Vercelli M, Rezza G, Cancer and AIDS Registry Linkage Study (2003) Risk of cancer in persons with AIDS in Italy, $1985-$ 1998. Br J Cancer 89: $94-100$

Dal Maso L, Serraino D, Franceschi S (2001b) Epidemiology of AIDSrelated tumours in developed and developing countries. Eur J Cancer 37: $1188-1201$

Dictor M, Attewell R (1988) Epidemiology of Kaposi's sarcoma in Sweden prior to the acquired immunodeficiency syndrome. Int $J$ Cancer 42: $346-351$

Franceschi S, Dal Maso L, Pezzotti P, Polesel J, Braga C, Piselli P, Serraino D, Tagliabue G, Federico M, Ferretti S, De Lisi V, La Rosa F, Conti E, Budroni M, Vicario G, Piffer S, Pannelli F, Giacomin A, Bellù F, Tumino R, Fusco M, Rezza G, Cancer and AIDS Registry Linkage Study (2003) Incidence of AIDS-defining cancers after AIDS diagnosis among people with AIDS in Italy, 1986-1998. J Acquir Immune Defic Syndr 34: 84-90

Franceschi S, Geddes M (1995) Epidemiology of classic Kaposi's sarcoma with special reference to Mediterranean population. Tumori 81: 308-314

Geddes M, Franceschi S, Balzi D, Arniani S, Gafà L, Zanetti R (1995) Birthplace and classic Kaposi's sarcoma in Italy. J Natl Cancer Inst 87: $1015-1017$

Geddes M, Franceschi S, Barchielli A, Falcini F, Carli S, Cocconi G, Conti E, Crosignani P, Gafà L, Giarelli L, Vercelli M, Zanetti R (1994) Kaposi's sarcoma in Italy before and after the AIDS epidemic. $\mathrm{Br} J$ Cancer 69: $333-336$ 
Guttman-Yassky E, Bar-Chana M, Yukelson A, Linn S, Friedman-Birnbaum R, Bergman R, Sarid R, Silbermann M (2003) Epidemiology of classic Kaposi's sarcoma in the Israeli Jewish population between 1960 and 1998. Br J Cancer 89: $1657-1660$

Hjalgrim H, Tulinius H, Dalberg J, Hardarson S, Frisch M, Melbye M (1998) High incidence of classical Kaposi's sarcoma in Iceland and the Faroe Islands. Br J Cancer 77: 1190-1193

International Agency for Research on Cancer Working Group on the Evaluation of Carcinogenic Risks to Humans (1996) Human immunodeficiency viruses and human T-cell lymphotropic viruses. IARC Monogr Eval Carcinog Risks Hum, Vol 67. IARC: Lyon

Iscovich J, Boffetta P, Franceschi S, Azizi E, Sarid R (2000) Classic Kaposi sarcoma. Epidemiology and risk factors. Int J Cancer 88: 500-517

Istituto Superiore di Sanità (2003) Aggiornamento dei casi di AIDS notificati in Italia al 30 giugno 2003. Notiziario ISS 16(Suppl 1): 1-15. Available at: http://www.iss.it/publ/noti/2003/03s3/03s3.pdf.

Mbulaiteye SM, Pfeiffer RM, Whitby D, Brubaker GR, Shao J, Biggar RJ (2003) Human herpesvirus 8 infection within families in rural Tanzania. J Infect Dis 187: $1780-1785$

Moore PS, Chang Y (1998) Kaposi's sarcoma (KS) KS-associated herpesvirus, and the criteria for causality in the age of molecular biology. Am J Epidemiol 147: $217-221$

Parkin DM, Muir CS, Whelan SL, Gao YT, Ferlay J, Powell J (eds) (1992) Cancer Incidence in Five Continents. IARC Sci Publ No. 120, Vol VI. IARC: Lyon

Parkin DM, Whelan SL, Ferlay J, Raymond L, Young J (eds) (1997) Cancer Incidence in Five Continents. IARC Sci Publ No. 143, Vol VII. IARC: Lyon

\section{Appendix}

Cancer and AIDS Registry Linkage Study: Pierluca Piselli (INMI 'L Spallanzani', Rome); Claudia Braga, Gary Clifford (IARC Lyon, France); Massimiliano Oggiano (Registro Tumori della Provincia di Sassari); Carmela Nicita (Registro Tumori Ragusa); Paolo Contiero (Registro Tumori Lombardia - Provincia di Varese); Stefano Rosso (Registro Tumori Piemonte, Torino); Maria Elisa Artioli (Registro Tumori della Provincia di Modena); Maria Antonietta Orengo (Registro Tumori Ligure, Genova); Pier Carlo Vercellino (Registro Tumori della Provincia di Biella); Loris Zanier (Registro Tumori del Friuli-Venezia Giulia); Fabio Vittadello
Parkin DM, Whelan SL, Ferlay J, Teppo L, Thomas DB (eds) (2002) Cancer Incidence in Five Continents. IARC Sci Publ No. 155, Vol. VIII. IARC: Lyon Perna AM, Bonura F, Vitale F, Viviano E, Di Benedetto MA, Ajello F, Villafrate MR, Prestileo T, Mancuso S, Goedert JJ, Romano N (2000) Antibodies to human herpes virus type 8 (HHV8) in general population and in individuals at risk for sexually transmitted diseases in Western Sicily. Int J Epidemiol 29: 175 - 179

Santarelli R, De Marco R, Masala MV, Angeloni A, Uccini S, Pacchiarotti R, Montesu MA, Satta R, Cerimele D, Faggioni A, Cottoni F (2001) Direct correlation between human herpesvirus- 8 seroprevalence and classic Kaposi's sarcoma incidence in Northern Sardinia. J Med Virol 65: $368-372$

Serraino D, Locatelli M, Songini M, Cirillo R, Bottazzo GF, Andreoni M, Franceschi S, Rezza S, Sardinia-Newborn Study Group (2001) Human herpes virus- 8 infection among pregnant women and their children: results from the Sardinia-IDDM Study 2. Int J Cancer 91: 740-741

Whitby D, Boshoff C (1998) Kaposi's sarcoma herpesvirus as a new paradigm for virus-induced oncongenesis. Curr Opin Oncol 10: 405-412

Whitby D, Luppi M, Barozzi P, Boshoff P, Weiss RA, Torelli G (1998) Human herpesvirus 8 seroprevalence in blood donors and lymphoma patients from different regions of Italy. I Natl Cancer Inst 90: 395 - 397

Wojcicki JM (2003) Traditional behavioural practices, the exchange of saliva and HHV-8 transmission in sub-Saharan African populations. $\mathrm{Br} J$ Cancer 89: 2016-2017

Zanetti R, Gafà L, Pannelli F, Conti E, Rosso S (eds) (2002) Cancer in Italy Incidence Data From Cancer Registries Vol 3, 1993-1998. Il Pensiero Scientifico Editore: Roma

(Registro Tumori dell'Alto Adige); Rosa Vattiato (Registro Tumori della Romagna, Forli); Carmen Fiorella Stocco (Registro Tumori del Veneto, Padova); Eugenio Paci (Registro Tumori Toscano, Firenze); Lidia Serventi (Registro Tumori della Provincia di Parma); Franco Pannelli (Registro Tumori Provincia di Macerata, Camerino); Maria Gentilini (Registro Tumori della Provincia di Trento); Francesco La Rosa (Registro Tumori Umbro); Valerio Ramazzotti, Maurilio Natali (Registro Tumori di Popolazione della Provincia di Latina); Mario Fusco, Maurizio Montella (Registro Tumori della Provincia di Napoli); Stefano Boros (Istituto Superiore di Sanità, Roma) 